\title{
PROTEIN-MEDIATED LIPID TRANSFER BETWEEN MONOLAYERS AND BILAYERS
}

\author{
R.A. DEMEL ${ }^{1}$, H. LOUWERS ${ }^{1}$, R.L. JACKSON ${ }^{2}$ and K.W.A. WIRTZ1 \\ ${ }^{1}$ Laboratory of Biochemistry, State University of Utrecht, Padualaan 8, $3584 \mathrm{CH}$, \\ Utrecht (The Netherlands) \\ ${ }^{2}$ Division of Lipoprotein Research, Department of Pharmacology and Cell Biophysics, \\ University of Cincinnati, College of Medicine, Cincinnati, OH 45267 (U.S.A.)
}

(Received 31 October 1983; accepted in final form 10 February 1984)

\begin{abstract}
An exchange of phosphatidylcholine (PC) is observed between two separate monolayers and between monolayer and vesicles in the presence of phosphatidylcholine transfer protein from beef liver (PC-TP). A coupled transfer of phosphatidylinositol (PI) from monolayer to phosphatidylcholine vesicles and a phosphatidylcholine transfer in the reverse direction is observed in the presence of bovine brain transfer protein (PI-TP). This protein shows an affinity for phosphatidylinositol which is more than 8 times higher than for phosphatidylcholine. PI-TP shows a lower specificity for phosphatidylcholine than PC-TP. However, sphingomyelin, which has a polar head group very similar to phosphatidylcholine, inhibits the lipid transfer as catalyzed by PI-TP. A transfer of cholesterol from monolayer to lipids, particularly those which form nonbilayer structures, is catalyzed by the nonspecific phospholipid transfer protein (ns-PL-TP). Monolayer studies indicate that the ns-PL-TP causes adsorption or fusion of vesicles with the lipid monolayer. A transfer of cholesterol from monolayer to vesicles was also catalyzed by the serum apoprotein apo $\mathrm{E}$.
\end{abstract}

\section{INTRODUCTION}

Biological membranes contain constituents with very low water solubility, such as phospholipids and cholesterol. These lipids can be transferred to aqueous media in a very specific way after interaction with transfer proteins. Proteins found in the cytosol fraction of tissues greatly stimulate phospholipid transfer between membranes in vitro (Wirtz, 1982). In eukaryotic cells, phospholipids are almost exclusively synthesized in the endoplasmic reticulum. The plasma membrane and other cellular membranes such as mitochondria have a limited capacity for phospholipid synthesis and depend on the endoplasmic reticulum for the supply of phosphatidylcholine and phosphatidylethanolamine. It has been suggested that transfer proteins could play a role in the transport of phospholipids from the endoplasmic reticulum and their insertion into membranes that lack the capacity of de novo phospholipid synthesis.

At present several transfer proteins have been purified and characterized ac- 
cording to their mode of action in vitro. The phosphatidylcholine (PC) transfer protein PC-TP specifically catalyzes the transfer of PC (Kamp et al., 1973), the phosphatidylinositol (PI) transfer protein PI-TP, which transfers PI but also PC (Helmkamp et al., 1976; Demel et al., 1977; DiCorleto and Zilversmit, 1979), and the nonspecific (phospholipid transfer protein ns-PL-TP which catalyzes the transfer of all phospholipids (except diphosphatidylglycerol) and also cholesterol (Bloj and Zilversmit, 1977). Recently, a cerebroside transfer protein has been purified from spleen (Metz and Radin, 1982) and brain (Abe and Sasaki, 1983) which facilitates the transfer of glucosylceramide, galactosylceramide and lactosylceramide, but not of other lipids from lipid vesicles to red cell ghests. The different specificities of these proteins and their unique property to insert and extract phospholipids from an interface make these proteins attactive models for the investigation of lipid-protein interactions. The measurement of transfer reactions in bulk systems requires a separation of the donor and acceptor membranes, which is difficult to achieve in a quantitative way.

Monomolecular layers offer the advantage of a well-controlled system. The molecular packing of the surface components can be changed and the release from the interface or transfer to the interface of lipid or protein can be monitored continuously (Demel, 1982). It is even possible to measure the transfer between two completely separated membrane interfaces, by having two monolayers separated by a bar and connected with a common subphase. As a further advantage, only small amounts of lipid $(2-10 \mathrm{nmol})$ are required. Ideally, in determing the specificity of transfer proteins the interfacial characteristics, e.g., packing of the bilayer, orientation of the polar head group, surface ion composition and concentration, should be identical for all phospholipids which the protein senses at the interface. In this respect the monolayer system is preferable to the bulk system.

\section{RESULTS AND DISCUSSION}

\section{Phosphatidylcholine transfer protein (PC-TP)}

The best-characterized transfer protein is PC-TP from beef liver, which interacts very specifically with PC and functions as a carrier of PC between membrane interfaces. The protein consists of a single chain of 213 amino acid residues interconnected by two disulfide bridges (Akeroyd et al., 1982), at $\mathrm{Cys}^{17}-\mathrm{Cys}^{63}$ and $\mathrm{Cys}^{93}-\mathrm{Cys}^{207}$. The protein contains five Trp residues at positions $30,81,101,186$ and 190. Tryptanoyl fluorescence indicates that they are buried in the hydrophobic region of the protein. There are three hydrophobic peptide regions: $\mathrm{Val}^{98}-\mathrm{-Val}-\mathrm{Tyr}-\mathrm{Trp}^{-}-\mathrm{Glu}^{-} \mathrm{Val}^{103}, \mathrm{Val}^{171}$--Phe-Met-Tyr-Tyr-Phe ${ }^{176}$, and $\operatorname{Trp}^{186}-\mathrm{Val}-\mathrm{Ile}-\mathrm{Asn}-\mathrm{Trp}-\mathrm{Ala}-\mathrm{Ala}^{192}$.

The surface pressure and radioactivity of the monolayer are recorded simultaneously during the experiment. The measurements are done at room temperature with $10 \mathrm{~m} M$ Tris buffer, $\mathrm{pH}$ 7.4. For most experiments a teflon 
trough was used: $5.4 \times 5.8 \mathrm{~cm}$ wide, $0.5 \mathrm{~cm}$ deep, volume $15 \mathrm{ml}$. A $1.5 \times 1.5$ $\mathrm{cm}$ extended corner with a hole of $0.8 \mathrm{~cm}$ was used to add protein and/or vesicles to the subphase.

In the absence of a monolayer the protein collected at the air-water interface until a final pressure of $12.5 \mathrm{mN} \mathrm{m}^{-1}$ was reached (Demel et al., 1973). The protein penetrated a 16:0/18:1 PC monolayer provided the initial lipid film pressure was below $20 \mathrm{mN} \mathrm{m}^{-1}$. Most of the transfer experiments were performed at pressures of $30 \mathrm{mN} \mathrm{m}^{-1}$, where the protein had no effect on the surface pressure. In fact, at lower surface pressures the same transfer rate was measured. This probably means that at a given time only very small amounts of protein are active at the interface, or that penetration of the protein is not required for its action. By varying the amount of PC-TP, it was demonstrated that the $\mathrm{PC}$ on the protein can exchange with $\mathrm{PC}$ in the monolayer and that 1 molecule of PC is bound per molecule of protein. (To measure a decrease in surface radioactivity in the presence of only transfer protein and in the absence of an acceptor membrane, rather high protein concentrations are required.) It can now be demonstrated that the PC-TP functions as a carrier in the transfer of $\mathrm{PC}$ from one monolayer to another. In this experiment the surface area of the trough was divided into two equal compartments by a fixed bar, having on side $1{ }^{14} \mathrm{C}$-labeled PC and on side 2 unlabeled PC. Injection of $\mathrm{PC}$-TP underneath the monolayer resulted in a decline of ${ }^{14} \mathrm{C}$-label in monolayer 1 and a concomitant increase of ${ }^{14} \mathrm{C}$-label in monolayer 2 . Since the surface pressure remained constant, unlabeled PC must have been transported simultaneously from monolayer 2 to monolayer 1 . The final value of the surface radioactivity accounts exactly for the introduction of unlabeled PC by injections of PC-TP into the subphase. The experiment demonstrates that the PC-TP is a true carrier in the sense that it moves freely through the subphase.

Small amounts of PC-TP have no effect on the surface radioactivity of a ${ }^{14} \mathrm{C}$-labeled PC monolayer (Fig. 1). On the addition of liposomes the surface radioactivity decreases while the surface pressure remains constant. The liposomal PC is in a 100 -fold excess of the monolayer PC $(1 \mu \mathrm{mol}$ vs $10 \mathrm{nmol})$. PC has to be present in both membrane interfaces for PC exchange to occur. The specificity of the interaction with respect to the polar head group is demonstrated by measuring the transfer of PC analogs. This suggests that the protein exposes a recognition site at the membrane interface that interacts with the phosphorylcholine head group. The transfer activity is adversely affected when the distance between phosphate group and quaternary nitrogen is altered or the quaternary nitrogen is modified, demonstrating that the molecular configuration of the polar head group should match the steric requirements of the recognition site (Kamp et al., 1977). Evidence for the importance of ionic interactions is supported by the observation that cations inhibit the PC-TP-mediated transfer in the following order: $\mathrm{La}^{3+}>\mathrm{Mg}^{2+} \geqslant \mathrm{Ca}^{2+}$ $>\mathrm{K}^{+} \equiv \mathrm{Na}^{+}$(Wirtz et al., 1976). It is in this order that these cations bind to the phosphodiester group of PC. This suggests that the recognition site contains basic amino acid residues involved in the interaction. Modification of 


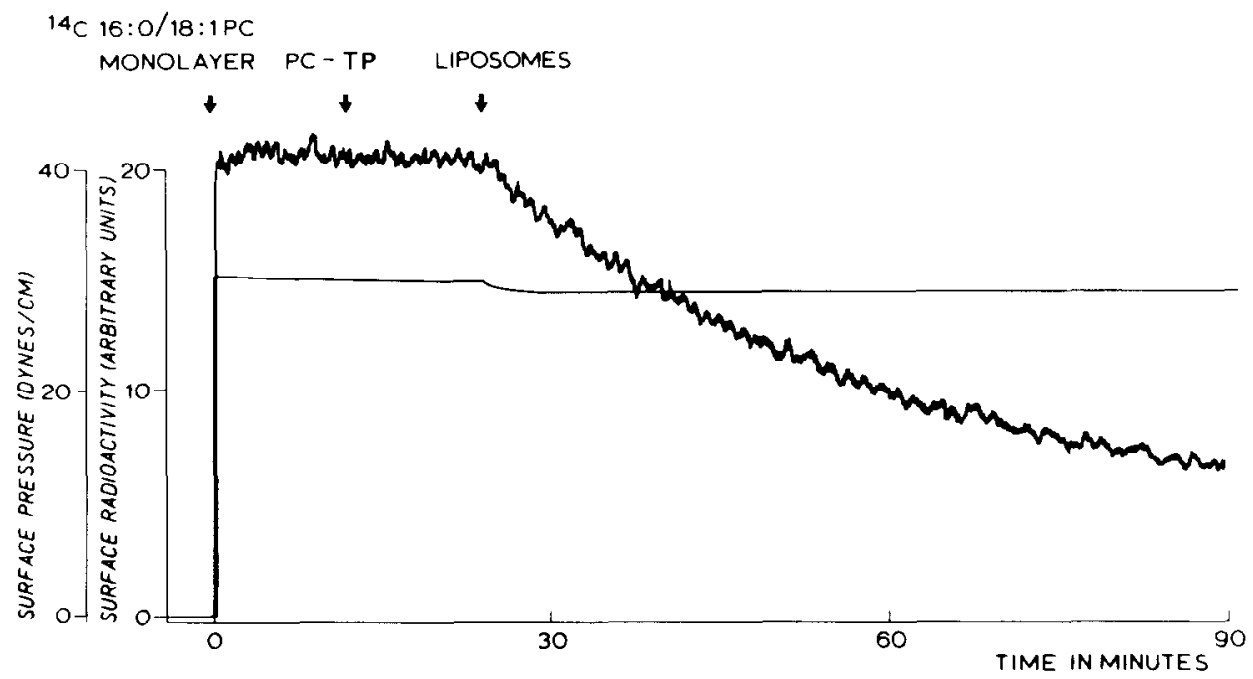

Fig. 1. Exchange of phosphatidylcholine between monolayer and vesicles. The monolayer consisted of $20.6 \mathrm{nmol} 16: 0 / 18: 1\left[{ }^{14} \mathrm{C}\right.$-methyl] phosphatidylcholine (PC); the subphase contained $1 \mu \mathrm{mol}$ sonicated liposomes (egg yolk phosphatidylcholine/phosphatidic acid; 96:4 mol\%) and $2.2 \mathrm{nmol}$ PC-TP. From the decrease of surface radioactivity it follows that $0.62 \mathrm{nmol}$ phosphatidylcholine is transferred to the subphase per minute. From: Demel et al. (1973).

3 of the Arg residues by butanedione completely inactivates the transfer protein (Akeroyd et al., 1981). In the presence of negatively charged vesicles, butanedione modifies 2 Arg residues without a significant loss of activity. This suggests that the phospholipid interface protects one Arg residue essential for the transfer activity and that Arg residues may play an important role in phospholipid-protein interaction. There is experimental evidence for strong hypdrophobic interactions between PC and the PC-TP and that the phospholipid is buried in a hydrophobic pocket of the protein. It has been shown (Kamp et al., 1975) that phospholipases have no effect on PC bound to PC-TP, whereas spin-labeled PC cannot be reduced by ascorbic acid (Devaux et al., 1977). Phosphatidylcholine with a fatty acid at the 2 -position, containing photosensitive groups, interacted with residues 168-175 (Wirtz, 1983). It is not known which peptides are involved in the binding of the fatty acid at the 1-position. The significance of the peptides 186-192 and 98-103 in the lipid binding is not yet established, although a derivative with only one fatty acid chain as lysophosphatidylcholine is not transferred by PC-TP. This suggests that one acyl chain is not sufficient to stabilize the interaction between phospholipid and PC-TP. Experiments with PC monolayers suggest that PC-TP forms a collision complex with the interface during the lifetime of which it exchanges its endogenous PC for one present in the interface. Exchange is observed when both membranes contain PC, although net transfer is observed in a number of cases to membranes devoid of PC. PC-TP can be a 
useful tool to exchange PC from the outer monolayer of membranes (Van Meer et al., 1980). When human erythrocytes and microsomes containing ${ }^{14} \mathrm{C}$-labeled $\mathrm{PC}$ were incubated in the presence of exchange proteins, about $75 \%$ of the erythrocyte PC was exchanged after $2 \mathrm{~h}$ and no additional exchange was observed. The results indicate that $75 \%$ of the PC is present in the outer layer. Furthermore, these experiments confirm earlier observations that there is no detectable transbilayer movement of PC in human erythrocytes. In rat erythrocytes, about $60-63 \%$ of $\mathrm{PC}$ was readily available for the exchange protein, but a second pool of PC appears to become available for exchange at a much lower rate. The calculated $t_{1 / 2}$ for transbilayer movement of $\mathrm{PC}$ in rat erythrocytes was $7-8 \mathrm{~h}$.

\section{Phosphatidylinositol transfer protein (PI-TP)}

Phosphatidylinositol (PI) is a special phospholipid among the main mcmbrane phospholipids, since its metabolism is affected by different external stimuli. The response can involve phosphorylation or degradation to phosphatidic acid (PA). Since PI cannot be resynthesized by the plasma membrane, a maintenance of PI levels would require a continuous supply from the microsomal fraction where the de novo synthesis of PI is located. A transfer protein with a preference for PI has been detected in the $105000 \mathrm{~g}$ supernatant fraction of brain synaptosomes and myelin (Wirtz et al., 1976a). The protein has been purified to homogeneity from bovine brain (Helmkamp et al., 1976; Demel et al., 1977) and heart (DiCorleto et al., 1979). PI-TP I and PI-TP II with isoelectric points of $\mathrm{pH} 5.2$ and 5.5, respectively, have a molecular weight of about 33000 . Incubations with microsomes labeled with either $\left[{ }^{3} \mathrm{H}\right] \mathrm{PI}$ or $\left[{ }^{14} \mathrm{C}\right] \mathrm{PC}$ and acceptor vesicles showed that both $\mathrm{PC}$ and PI are transferred. If it is taken into account that rat liver microsomes contain 10X as much PC as PI and the activity is expressed as the percentage of each microsomal pool, it follows that PI-TP transfers PI $12 \times$ faster than PC. The mode of action of PI-TP can be investigated under controlled conditions by the phospholipid monolayer technique (Demel et al., 1977). As shown in Fig. 2, a monolayer was spread at the air-water interface, consisting of an equimolar mixture of rat microsomal PI and 16:0/18:1 PC, where either PC or PI were ${ }^{14} \mathrm{C}$-labeled. Injection of liposomes (PC-PI 98:2 mol\%) under these monolayers hardly affected the film pressure (i.e., $30 \mathrm{mN} \mathrm{m}^{-1}$ ) nor the surface radioactivity. Subsequent injections of PI-TP in the subphase reduced the surface radioactivity by $0.64 \% \mathrm{~min}^{-1}$, when the mixed monolayers contained $\left[{ }^{14} \mathrm{C}\right] \mathrm{PC}$ and by $5 \% \mathrm{~min}^{-1}$ with $\left[{ }^{14} \mathrm{C}\right] \mathrm{PI}$ in the monolayer. In this experiment, PI-TP transfers PI about $8 \times$ more rapidly than PC to the vesicles. During this transfer process the film pressure remained constant, indicating the insertion of PI and/or PC from the liposomes into the monolayer. Bovine PI-TP also transferred PI between a monolayer of pure $\left[{ }^{14} \mathrm{C}\right] \mathrm{PI}$ and vesicles or pure PC. In order to establish whether loss of PI from the interface is compensated for by PC from the vesicles, the epxeriment was also performed 


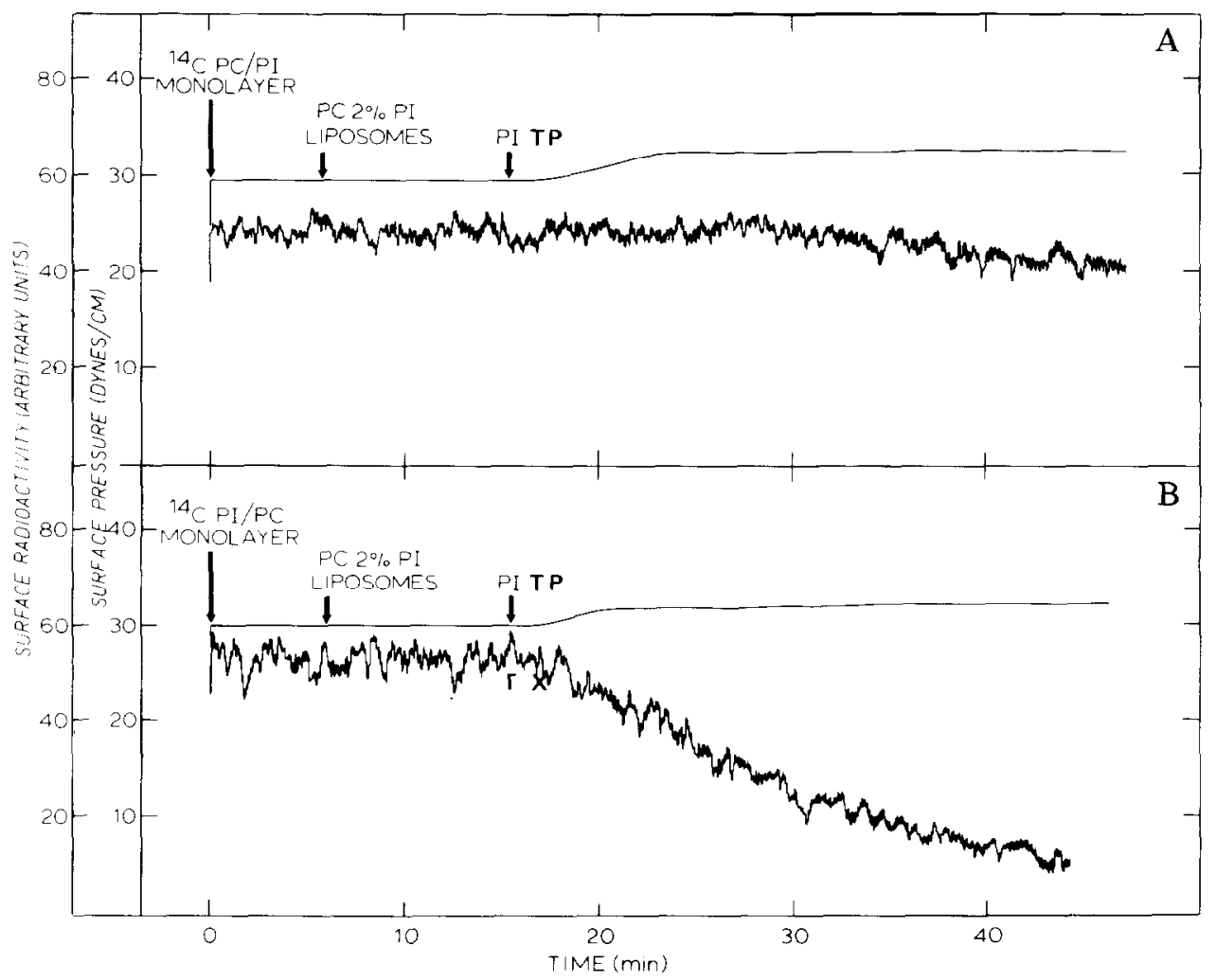

Fig. 2. (A) Transfer of phosphatidylcholine (PC) between monolayer and liposomes. The monolayer consisted of a mixed monolayer of $6 \mathrm{nmol} 16: 0 / 18: 1\left[{ }^{14} \mathrm{C}\right.$-methyl] phosphatidylcholine and rat liver microsomal phosphatidylinositol (PI), molar ratio 1:1; the liposomes consisting of egg yolk phosphatidylcholine and $2 \%$ phosphatidylinositol. The subphase contained $1 \mu \mathrm{mol}$ liposomal phosphatidylcholine and $6 \mathrm{nmol}$ transfer protein isolated from beef brain in $10 \mathrm{~m} M$ Tris- $\mathrm{HCl}$ buffer, $1 \mathrm{~m} M$ EDTA (pH 7.4). (B) Transfer of phosphatidylinositol (PI) between monolayer and liposomes. The procedure was similar to that described in (A), except that phosphatidylinositol was ${ }^{14} \mathrm{C}$-labeled instead of phosphatidylcholine. From: Demel et al. (1977).

when the monolayer consisted of unlabeled PI and the vesicles of $\left[{ }^{14} \mathrm{C}\right] \mathrm{PC}$ (Zborowski and Demel, 1982). Collection of the interface at the end of incubation demonstrated that the interface contained $7.4 \mathrm{nmol}$ of $\left[{ }^{14} \mathrm{C}\right] \mathrm{PC}$ as compared to a loss of $7.6 \mathrm{nmol}$ of $\left[{ }^{14} \mathrm{C}\right] \mathrm{PI}$ (i.e., 90\%) from the monolayer. This experiment shows that PI-TP can catalyze a net transfer of PI to PC vesicles which is compensated for by a net transfer of PC to the PI monolayer. It appears that a mechanism of true molecular exchange underlies the net transfer observed (see also Kasper and Helmkamp, 1981). Replacement of the PI monolayer for PS* or PA* gave virtually no transfer of $\left[{ }^{14} \mathrm{C}\right] \mathrm{PC}$ to the monolayer, indicating that PI-TP cannot effectively exchange vesicle PC for either of these acidic phospholipids. On the other hand, a similar experiment with a

*Phosphatidylserine (PS); phosphatidic acid (PA). 
PG monolayer strongly suggested that PI-TP can exchange vesicle PC for PG*. It has also been determined whether or not PI-TP can catalyze transfer of PI between a monolayer of $\left[{ }^{14}\right]$ PI (monolayer 1 ) and a monolayer of unlabeled PC (monolayer 2). These monolayers, separated by a surface barrier, were connected by a common subphase. Injection of PI-TP into the subphase yielded a time-dependent removal of $\left[{ }^{14} \mathrm{C}\right]$ PI from monolayer 1 but virtually no transfer of $\left[{ }^{14} \mathrm{C}\right]$ PI to monolayer 2 . Since the surface pressure of monolayer 1 remained constant, removal of $\left[{ }^{14} \mathrm{C}\right] \mathrm{PI}$ from the monolayer must signify binding to PI-TP in exchange for phospholipid molecules already present on the protein. The minimal amounts of $\left[{ }^{14} \mathrm{C}\right] \mathrm{PI}$ detected in monolayer 2 indicates that PI-TP does not readily exchange its bound $\left[{ }^{14} \mathrm{C}\right] \mathrm{PI}$ for PC from the monolayer. In separate experiments we observed that $\left[{ }^{14} \mathrm{C}\right] \mathrm{PI}$ bound to PI-TP exchanged with a PC monolayer at a rate of $0.4 \mathrm{pmol} / \mathrm{nmol}$ protein per min. For comparison, $\left[{ }^{14} \mathrm{C}\right] \mathrm{PC}$ bound to PI-TP exchanged with a PI monolayer at a rate of $7.5 \mathrm{pmol} / \mathrm{nmol}$ protein per min. This clearly shows that PITP has a much greater affinity for PI than PC. The reason for the observed rapid net transfer of PI from the monolayer to $\mathrm{PC}$ vesicles in the subphase must be due to the great excess of vesicle PC $(1 \mu \mathrm{mol})$ over monolayer PI $(6 \mathrm{nmol})$. It appears that net transfer of PI is the result of the relative affinities of PI-TP for PI and PC and the pool sizes involved. The specificity of the interaction with respect to the polar head group of $\mathrm{PC}$ is demonstrated by measuring the transfer of $\left[{ }^{14} \mathrm{C}\right] \mathrm{PI}$ from the monolayer to different vesicles of PC analogue (Demel et al., 1982). The transfer activity is affected by the distance between the phosphate group and the quaternary nitrogen and by demethylation of the quaternary nitrogen, but to a lesser extent than was found for PC-TP. On the other hand, sphingomyelin, which has a polar head group very similar to PC, has a very strong inhibitory effect, although significant binding of $\left[{ }^{14} \mathrm{C}\right]$ sphingomyelin to PI-TP could not be demonstrated. Since PI-TP interacts very strongly with a negatively charged phospholipid such as PI, it might be expected that cations would affect the transfer reaction. This is not the case. Monovalent cations do not reduce the transfer rate, neither do low concentrations $(\sim 1 \mathrm{mM})$ of divalent ions. Higher concentrations cause an enormous increase in surface pressure, probably due to an adsorption of PC vesicles onto the PI monolayer, which reduces the transfer rate to zero. The fatty acid composition of $\mathrm{PC}$ affects the transfer reaction in such a way that a higher fluidity of the fatty acyl chains, as polyunsaturation of both chains or shortening of the chains, reduces the transfer rate. Ether or alkyl linkages also reduce the transfer rate. The PC stereoisomer with the fatty acids at the 1,3-position instead of on the 1,2-position is incapable of being transferred. It is suggested that PI-TP has one recognition site for PI and one for the PC head group, with one mutual hydrophobic binding site to accomodate the fatty acyl chains. The structure of the PI-TP is not yet elucidated. It is known, however, that a sulfhydrylgroup might be essential, since the transfer protein is inhibited by $N$-ethylmaleimide. Studies labeling the PI$\mathrm{TP}$ with ${ }^{125}$ I showed that only very low concentrations of protein are present at the interface at a given time.

*Phosphatidylglycerol (PG). 
It can be suggested from these studies that PC-TP and PI-TP could have a function in the transfer of lipids between different membrane systems. However, under the experimental conditions used in vitro only little net mass transfer could be measured. It is also possible that these proteins are involved in controlling the dynamic properties of biological membranes.

\section{Nonspecific phospholipid transfer protein (ns-PL-TP)}

The vesicle-liposome assay indicated that the ns-PL-TP can transfer all commonly occurring phospholipids, except for diphosphatidylglycerol, but also transfers cholesterol (Crain and Zilversmit, 1980). It remains to be established that ns-PL-TP acts as a carrier. The transfer of cholesterol is especially interesting. Cholesterol, which is a very hydrophobic membrane compound, is found to equilibrate very fast between different membrane structures (De Grella and Simoni, 1982), whereas cholesterol levels are thought to be associated with arterial diseases. It may be assumed that the ns-PL-TP contains a hydrophobic binding site, yet lacks specific recognition sites. The ns-PL-TP isolated from beef liver was purified according to a modified procedure as described by Crain and Zilversmit (1980). The octylsepharose purification step was omitted and the heat treatment was performed at $85^{\circ} \mathrm{C}$ for $3 \mathrm{~min}$. A ns-PL-TP concentration-dependent release of $\left[{ }^{14} \mathrm{C}\right] \mathrm{PI}$ from a monolayer could be measured. The ns-PL-TP is much more surface-active than the other transfer proteins. The injection of ns-PL-TP underneath a monolayer of PI of $28 \mathrm{mN} \mathrm{m}^{-1}$ caused a pressure increase of $8.5 \mathrm{mN} \mathrm{m}^{-1}$. A decrease in surface radioactivity is already initiated by the injection of the transfer protein, whereas the subsequent injection of $\mathrm{PC}-2 \% \mathrm{PA}$ vesicles has only a small addi-

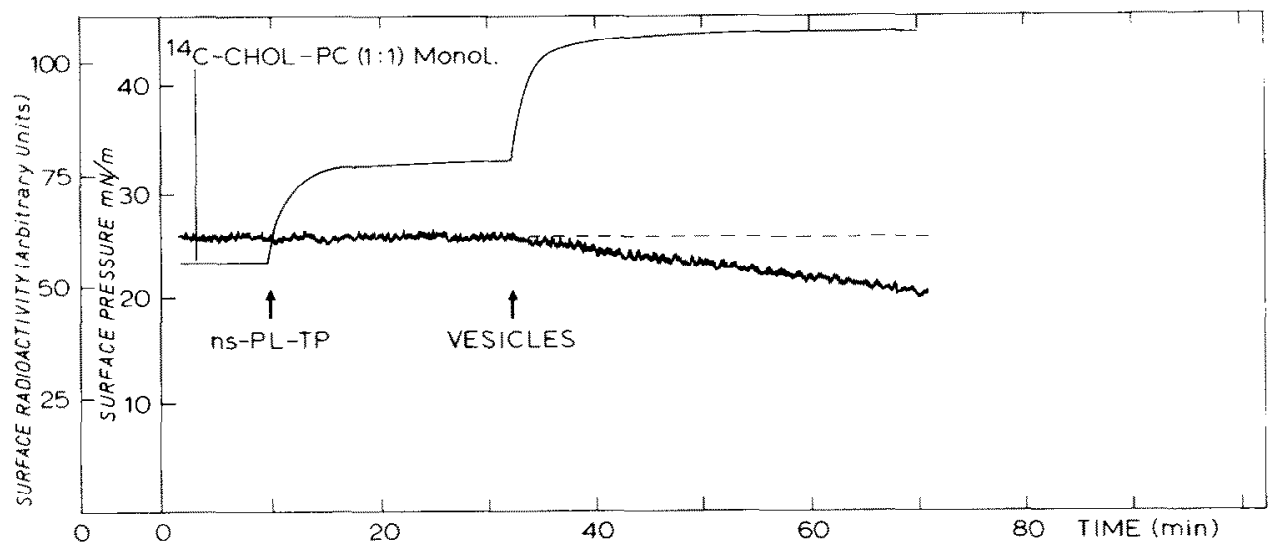

Fig. 3. Transfer of $\left[4{ }^{14} \mathrm{C}\right]$ cholesterol from monolayer to vesicles. The monolayer consisted of a mixed monolayer of $6 \mathrm{nmol}\left[4^{-14} \mathrm{C}\right]$ cholesterol and dioleoylphosphatidylcholine (PC), molar ratio $1: 1$. The vesicles consisted of phosphatidylcholine:phosphatidylethnolamine: diphosphatidylglycerol (58:31:11, molar ratio). The subphase contained $1 \mu$ mol liposomal lipid and $100 \mathrm{nmol} \mathrm{ns-PL-TP}$ isolated from beef liver in $10 \mathrm{mM}$ Tris-HCl buffer ( $\mathrm{pH} 7.4$ ). 
tional effect on the surface radioactivity and surface pressure. This could indicate that PI from the monolayer is strongly bound to the protein. Transfer of $\left[{ }^{14} \mathrm{C}\right]$ cholesterol from a mixed monolayer of PC-cholesterol (1:1 molar ratio) did not start after the injection of ns-PL-TP but was initiated when PC-PEDPG vesicles (molar ratio 58:31:11) were also injected (Fig. 3). PC-2\% PA vesicles were not very effective in this respect. Injection of ns-PL-TP underneath a PC-cholesterol monolayer of $24 \mathrm{mN} \mathrm{m}^{-1}$ caused a pressure increase of $9 \mathrm{mN} \mathrm{m}^{-1}$. The injection of the PC-PE-DPG vesicles caused a further increase of $12 \mathrm{mN} \mathrm{m}^{-1}$, so that the final film pressure reached $\sim 45 \mathrm{mN} \mathrm{m}^{-1}$. Labeling of the PC-PE-DPG vesicles with $\left[{ }^{14} \mathrm{C}\right] \mathrm{PC}$ demonstrated that the amount of label collected at the interface was far larger than the expected loss of cholesterol from the interface under these conditions. This might indicate that the ns-PL-TP causes an adsorption or fusion of vesicles with the lipid monolayer. This idea is supported by the finding that PC-cholesterol (1:1 molar ratio) vesicles show a significant increase in particle size in the presence of ns-PL-TP as visualized by freeze-etch electron microscopy.

\section{Apoprotein $E$}

It has been shown that specific lipid-protein interactions and lipid transfer reactions can also occur in serum (Jackson et al., 1979). All serum apoproteins showed a rather high surface activity and when injected underneath a lipid monolayer of $20 \mathrm{mN} \mathrm{m}^{-1}$ they increased the film pressure to about 30 $\mathrm{mN} \mathrm{m}^{-1}$. Cholesterol transport in serum is also an intriguing question. It has

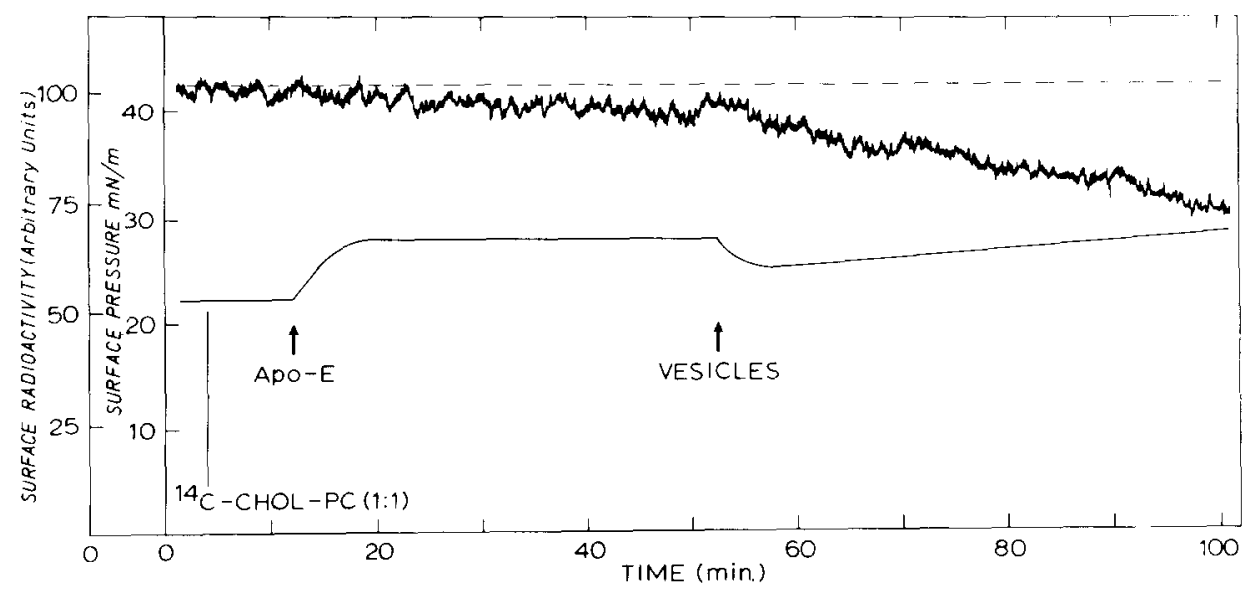

Fig. 4. The effect of apo $\mathrm{E}$ on mixed monolayers of dioleoylphosphatidylcholine (PC) and cholesterol (chol.). The monolayer consisted of a mixed monolayer of $6 \mathrm{nmol}$ dioleoylphosphatidylcholine and $\left[4-{ }^{14} \mathrm{C}\right]$ cholesterol, molar ratio $1: 1$. The subphase contained 15 $\mathrm{ml}$ of $0.05 \mathrm{M}$ Tris- $\mathrm{HCl}, \mathrm{pH} 7.4$. The experiment was performed at $37^{\circ} \mathrm{C}$. At the indicated time $25 \mu \mathrm{g}$ apo $\mathrm{E}$ was added to the subphase. At the indicated time $1 \mu \mathrm{mol}$ of liposomal egg phosphatidylcholine containing 2 mol\% phosphatidic acid was added to the subphase. 
been known for a long time that an increase in serum cholesterol level is accompanied by an increase in apo $\mathrm{E}$ (arginine-rich protein). Apo $\mathrm{E}$ can be isolated from VLDL (very low density proteins) obtained from plasma of cholesterol-fed pigs (Jackson, 1977). A monomolecular film of $\left[4{ }^{14} \mathrm{C}\right]$ cholesterol$\mathrm{PC}\left(1: 1\right.$ molar ratio) is formed to give an initial pressure of $22.8 \mathrm{mN} \mathrm{m}^{-1}$.

After the injection of apo $\mathrm{E}$ the pressure increased with $6.2 \mathrm{mN} \mathrm{m}^{-1}$ and the surface radioactivity decreased slightly (Fig. 4). After the injection of $\mathrm{PC}-2 \%$ $\mathrm{PA}$ vesicles there is a significant release of $\left[{ }^{14} \mathrm{C}\right]$ cholesterol from the interface, whereas there is no significant change in surface pressure except immediately after the injection of the vesicles, when there is a temporary reduction. The experiments suggest an interaction of apo $\mathrm{E}$ with cholesterol which could be of importance for the transfer of cholesterol from VLDL during lipolysis.

\section{ACKNOWLEDGEMENTS}

Part of this work was supported by U.S. Health Service Grants HL-22619 and HL-23019, and by a General Clinical Research Center and CLINFO Grant RR-00068.

\section{REFERENCES}

Abe, A. and T. Sasaki, 1983. Submitted.

Akeroyd, R., L.G. Lange, J. Westerman and K.W.A. Wirtz, 1981. Eur. J. Biochem., 121: $77-81$.

Akeroyd, R., J.A. Lenstra, J. Westerman, G. Vriend, K.W.A. Wirtz and L.L.M. van Deenen, 1982. Eur. J. Biochem., 121: 391-394.

Bloj, B. and D.B. Zilversmit, 1977. Biol. Chem., 252: 1613-1619.

Crain, R.C. and D.B. Zilversmit, 1980. Biochemistry, 19: 1433-1439.

De Grella, R.F. and R.D. Simoni, 1982. J. Biol. Chem., 257: 14256-14262.

Demel, R.A., 1982. In: A. Martonosi (Ed.), Membrane and Transport, Vol. 1, Plenum, New York, NY, pp. 159-164.

Demel, R.A., K.W.A. Wirtz, H.H. Kamp, W.S.M. Geurts van Kessel and L.L.M. van Deenen, 1973. Nature (London), 246: 102-105.

Demel, R.A., R. Kalsbeek, K.W.A. Wirtz and L.L.M. van Deenen, 1977. Biochim. Biophys. Acta, 466: 10-22.

Demel, R.A., B.G.M. van Bergen, A.L.G. van den Eeden, J. Zborowski and L.H.K. Defize, 1982. Biochim. Biophys. Acta, 710: 264-270.

Devaux, P.F., P. Moonen, A. Bienvenue and K.W.A. Wirtz, 1977. Proc. Natl. Acad. Sci. U.S.A., 74: 1807-1810.

DiCorleto, P.E. and D.B. Zilversmit, 1979. Biochim. Biophys. Acta, 552: 114-119.

DiCorleto, P.E., J.B. Warach and D.B. Zilversmit, 1979. J. Biol. Chem., 254: 7795-7802.

Helmkamp, G.M., S.A. Nelemans and K.W.A. Wirtz, 1976. Biochim. Biophys. Acta, 424 : $168-182$.

Jackson, R.L., J.D. Morrisett, H.J. Pownall, A.M. Gotto, A. Kamio, H. Imai, R. Tracy and F.A. Kummerow, 1977. J. Lipid Res., 18: 182-190.

Jackson, R.L., F. Pattus and R.A. Demel, 1979. Biochim. Biophys. Acta, 556: 369-387.

Kamp, H.H., K.W.A. Wirtz and L.L.M. van Deenen, 1973. Biochim. Biophys. Acta, 318: $313-325$. 
Kamp, H.H., K.W.A. Wirtz and L.L.M. van Deenen, 1975. Biochim. Biophys. Acta, 398: $401-414$.

Kamp, H.H., K.W.A. Wirtz, P.R. Baer, A.J. Slotboom, A.F. Rosenthal, F. Paltauf and L.L.M. van Deenen, 1977. Biochemistry, 16:1310-1316.

Kasper, A.M. and G.M. Helmkamp, 1981. Biochim. Biophys. Acta, 664: 22-32.

Metz, R.J. and N.S. Radin, 1982. J. Biol. Chem., 257: 12901-12907.

Van Meer, G., B.J.H.M. Poorthuis, K.W.A. Wirtz, J.A.F. Op den Kamp and L.L.M. van Deenen, 1980. Eur. J. Biochem., 103: 283-288.

Wirtz, K.W.A., W.S.M. Geurts van Kessel, H.H. Kamp and R.A. Demel, 1976. Eur. J. Biochem., 61: 515-523.

Wirtz, K.W.A., J. Jolles, J. Westerman and F. Neys, 1976a. Nature (London) 260: 354355 .

Wirtz, K.W.A., 1982. In: P.C. Jost and O.H. Griffith (Eds), Lipid-Protein Interactions, Vol. 1, Wiley, New York, NY, pp. 151-231.

Wirtz, K.W.A., R. Akeroyd, J. Westerman, and L.L.M. van Deenen, 1983. In: H. Sund and C. Veeger (Eds), Mobility and Recognition in Cell Biology, W. de Gruyter, Berlin, pp. $253-264$.

Zborowski, J. and R.A. Demel, 1982. Biochim. Biophys. Acta, 688: 381-387. 